Supporting Information

\title{
Zinc Oxo Clusters Improve the Optoelectronic Properties on Indium Phosphide Quantum Dots
}

Kangyong Kim, ${ }^{\dagger, \S}$ Yo-Han Suh, ${ }^{\dagger, \S}$ Dohoon Kim,,${ }^{\ddagger} \S$ Yonghoon Choi, ${ }^{\dagger}$ Eunbyul Bang,, Byung Hyo Kim, ${ }^{\perp}$ and Jongnam Park*,†

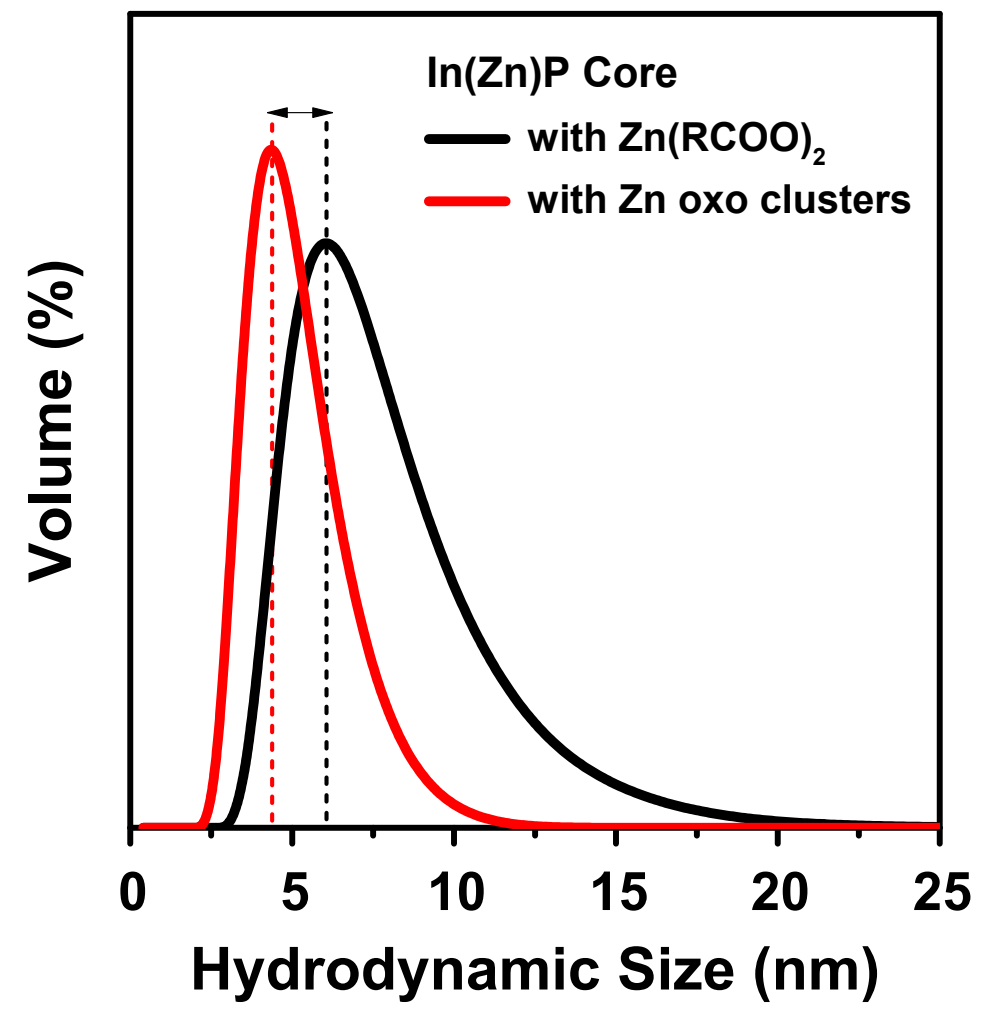

Figure S1. DLS characterization of $\operatorname{In}(\mathrm{Zn}) \mathrm{P}$ core with different zinc precursors. (Solvent: hexane) 

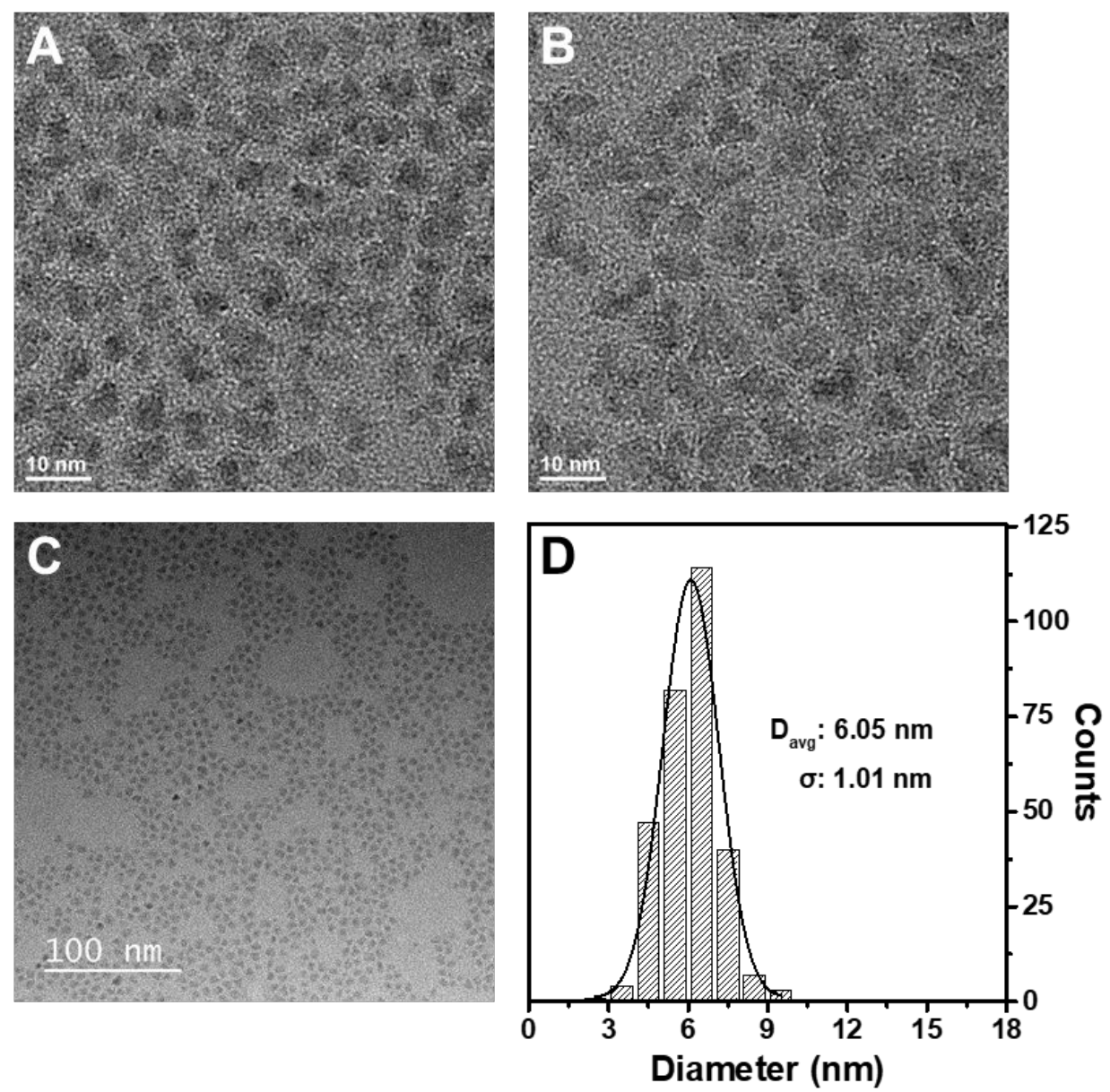

Figure S2. TEM images of In(Zn)P@ZnSeS QDs

(A. QDs with Zn-oxo clusters, B. QDs without Zn-oxo clusters,

C. QDs with Zn-oxo clusters (Low magnification),

D. Size distribution histogram and Gaussian fit of QDs with Zn-oxo clusters)

\begin{tabular}{cccccc}
\hline Material & $\tau_{1}\left(f_{1}\right) / \mathrm{ns}$ & $\tau_{2}\left(f_{2}\right) / \mathrm{ns}$ & $\tau_{3}\left(f_{3}\right) / \mathrm{ns}$ & $\chi^{2}$ & $\tau_{\text {avg }} / \mathrm{ns}$ \\
\hline In(Zn)P@ZnSeS & 4.89 & 33.93 & 78.33 & 1.00 & 42.81 \\
with Zn oxo clusters & $(0.07)$ & $(0.68)$ & $(0.25)$ & & \\
& & & & & \\
w/o Zn oxo clusters & 11.45 & 36.11 & 110.14 & 1.01 & 39.33
\end{tabular}

Table S1. Fitted Parameters of TRPL Spectra 


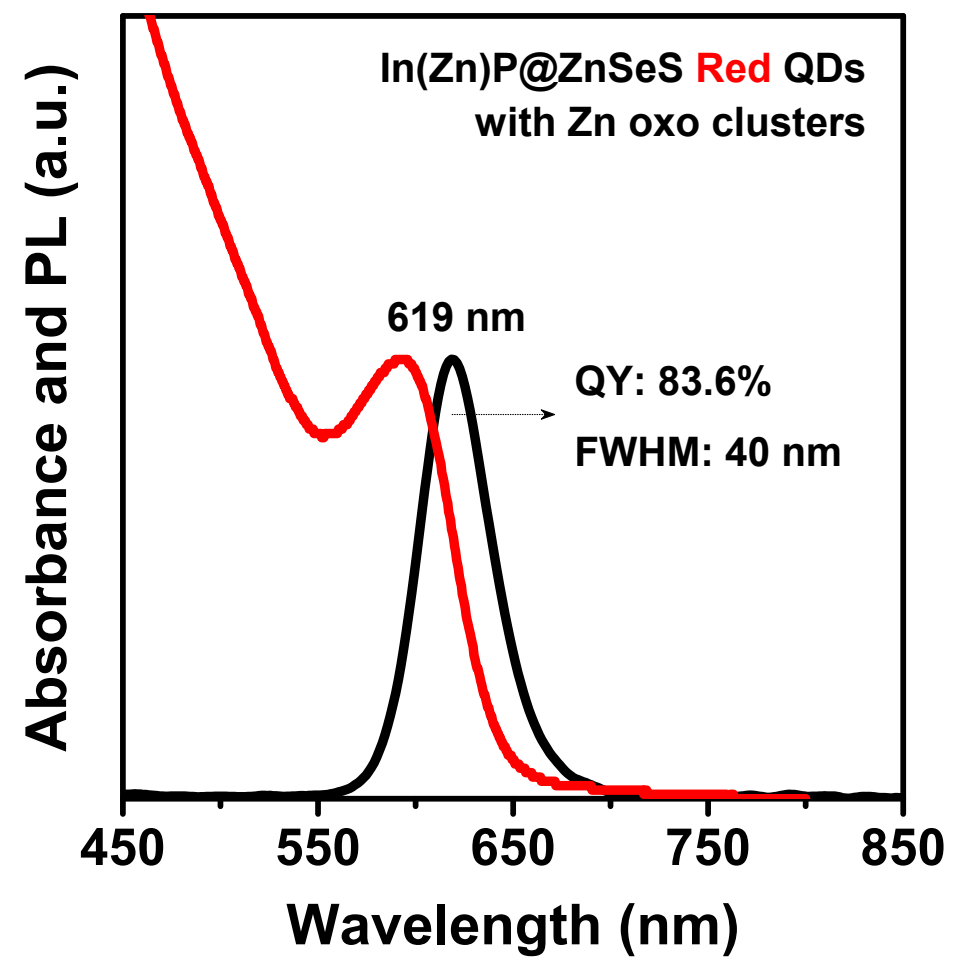

Figure S3. Absorbance and photoluminescence of $\operatorname{In}(\mathrm{Zn}) \mathrm{P} @ \mathrm{ZnSeS}$ red QDs with Zn oxo clusters

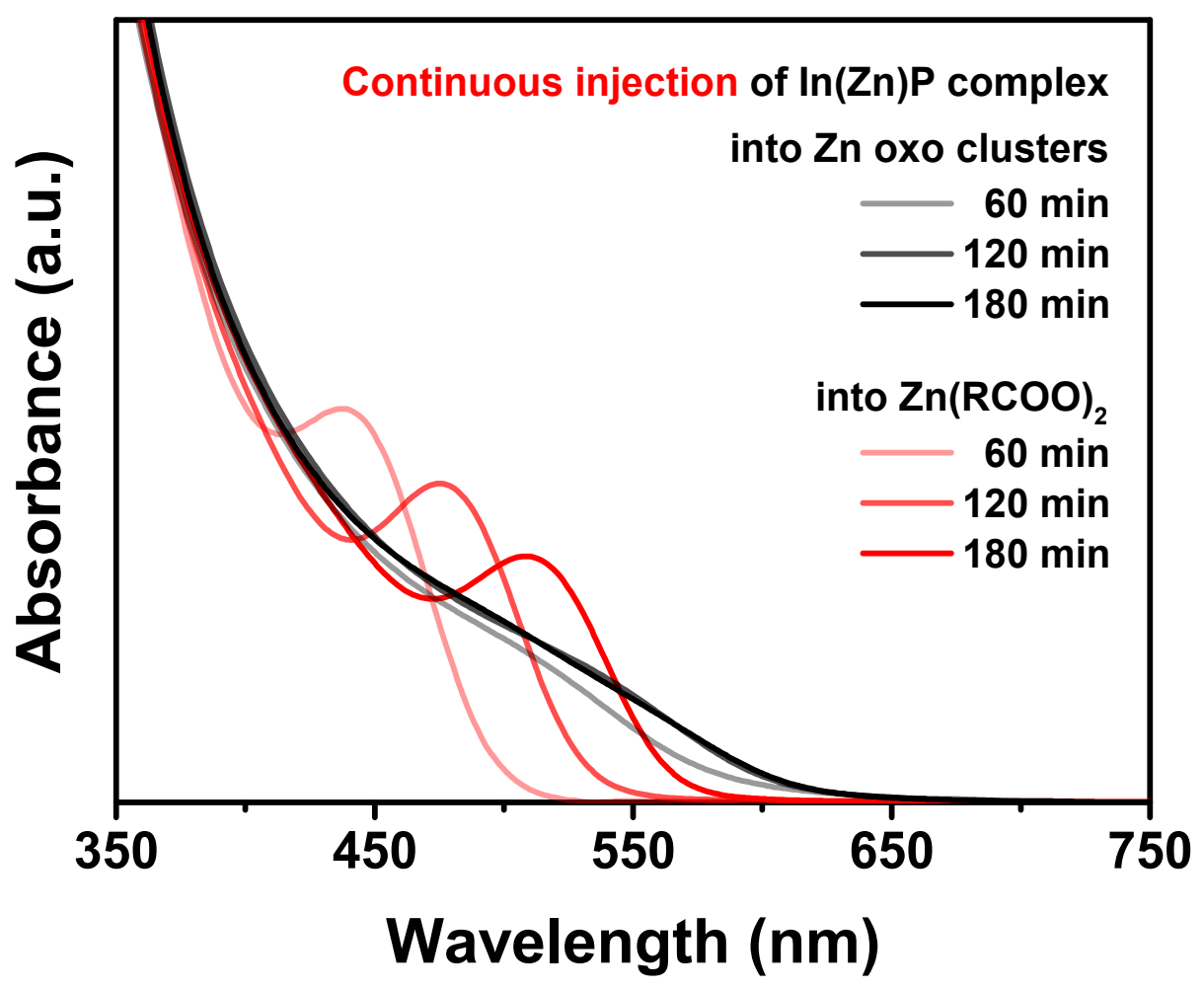

Figure S4. Changes of the absorption spectrum during continuous injection of $\operatorname{In}(\mathrm{Zn}) \mathrm{P}$ complex into different $\mathrm{Zn}$ precursor solution without seeds 


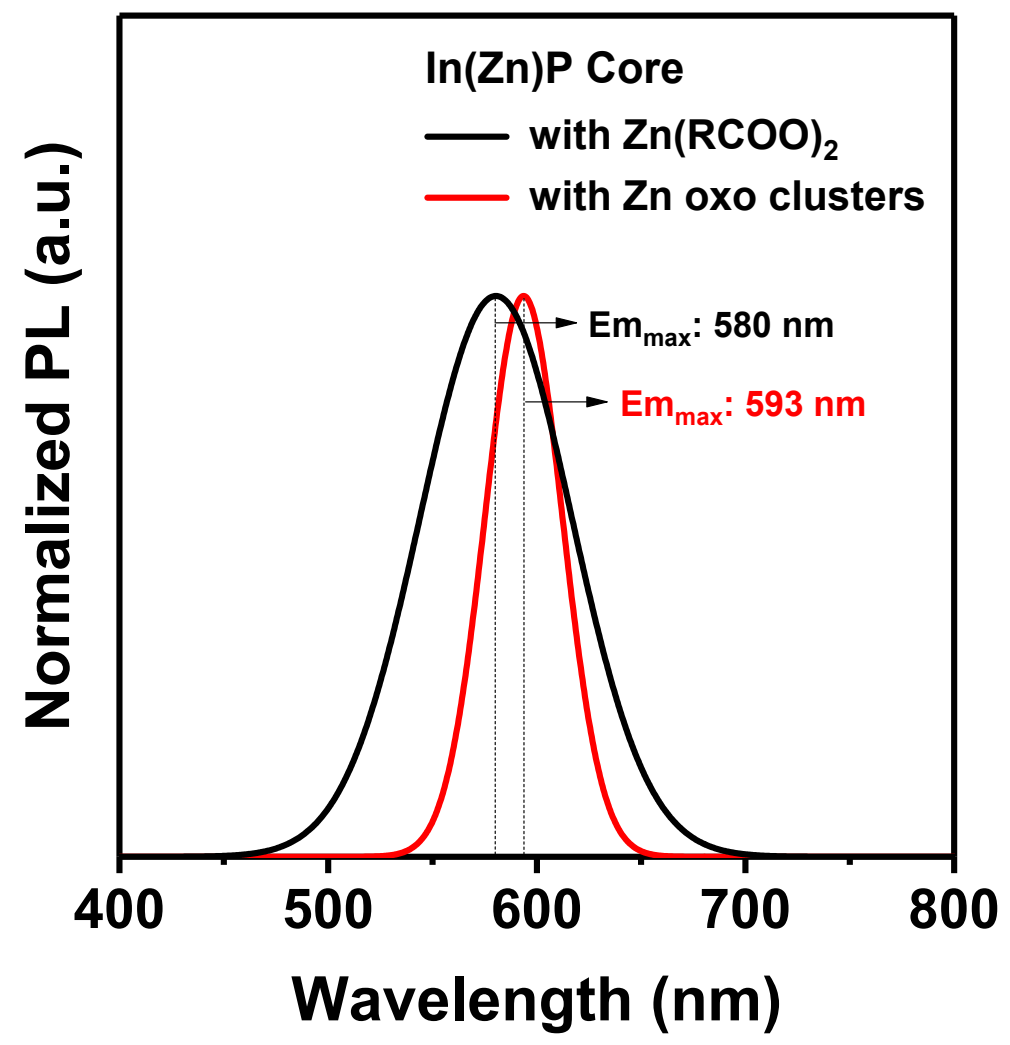

Figure S5. Normalized photoluminescence of $\operatorname{In}(\mathrm{Zn}) \mathrm{P}$ cores grown to have similar emission wavelengths

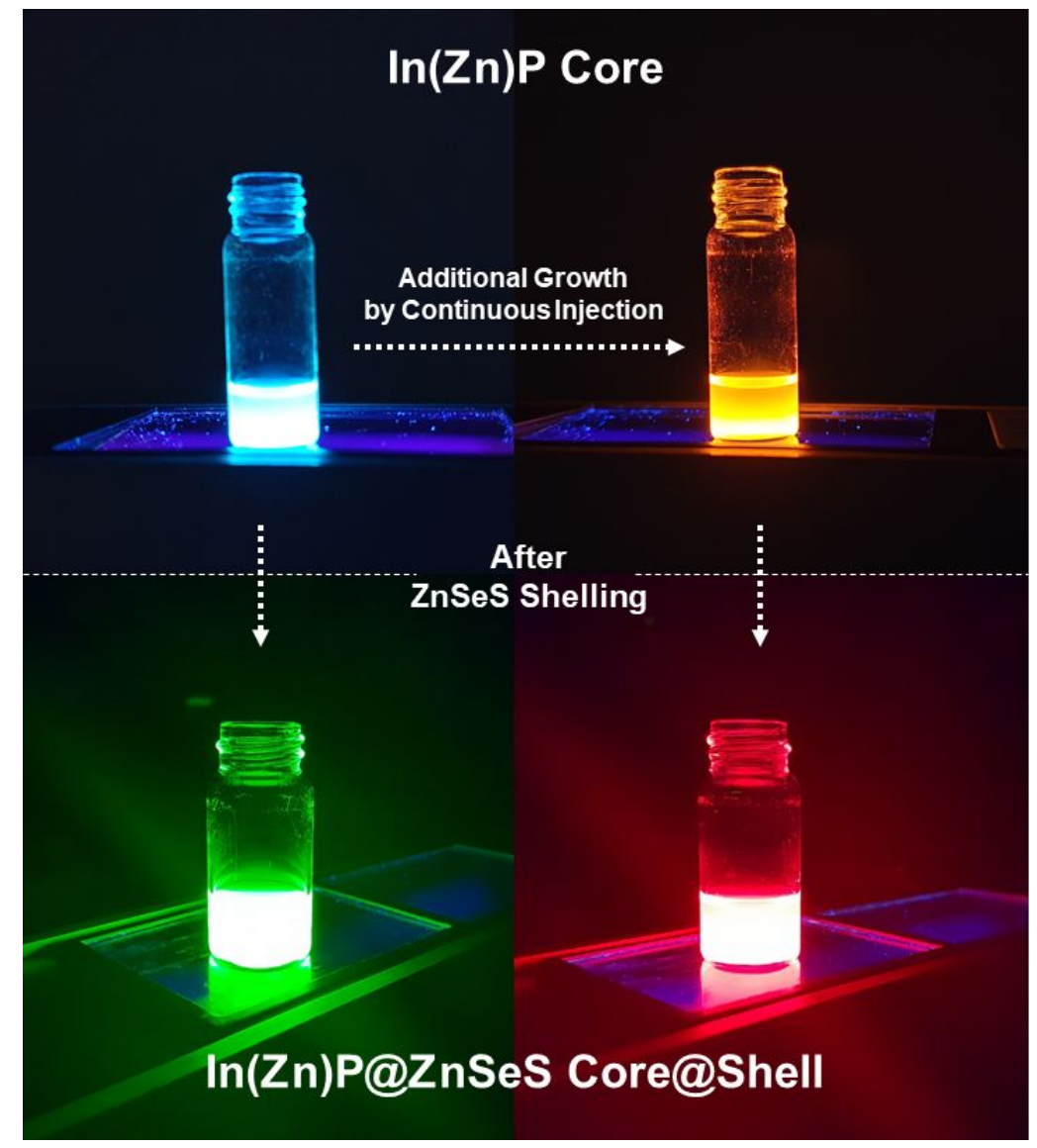

Figure S6. Photo images of In(Zn)P core and In(Zn)P@ZnSeS core@shell QDs 
(a)
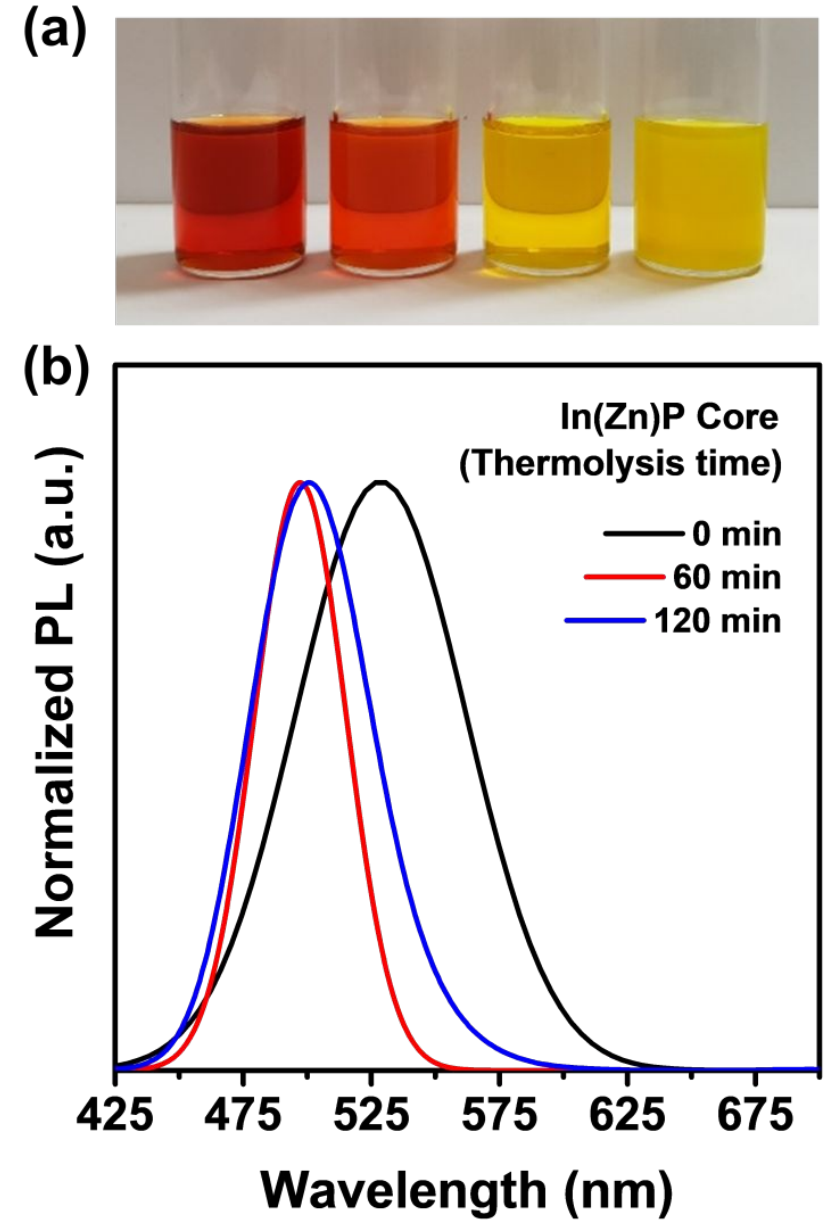

Figure S7. (a) Photo images of $\operatorname{In}(\mathrm{Zn}) \mathrm{P}$ cores with different thermolysis time of zinc precursors. (from left) 10, 30, 60, 120 min respectively.

(b) Normalized photoluminescence results with different thermolysis time 


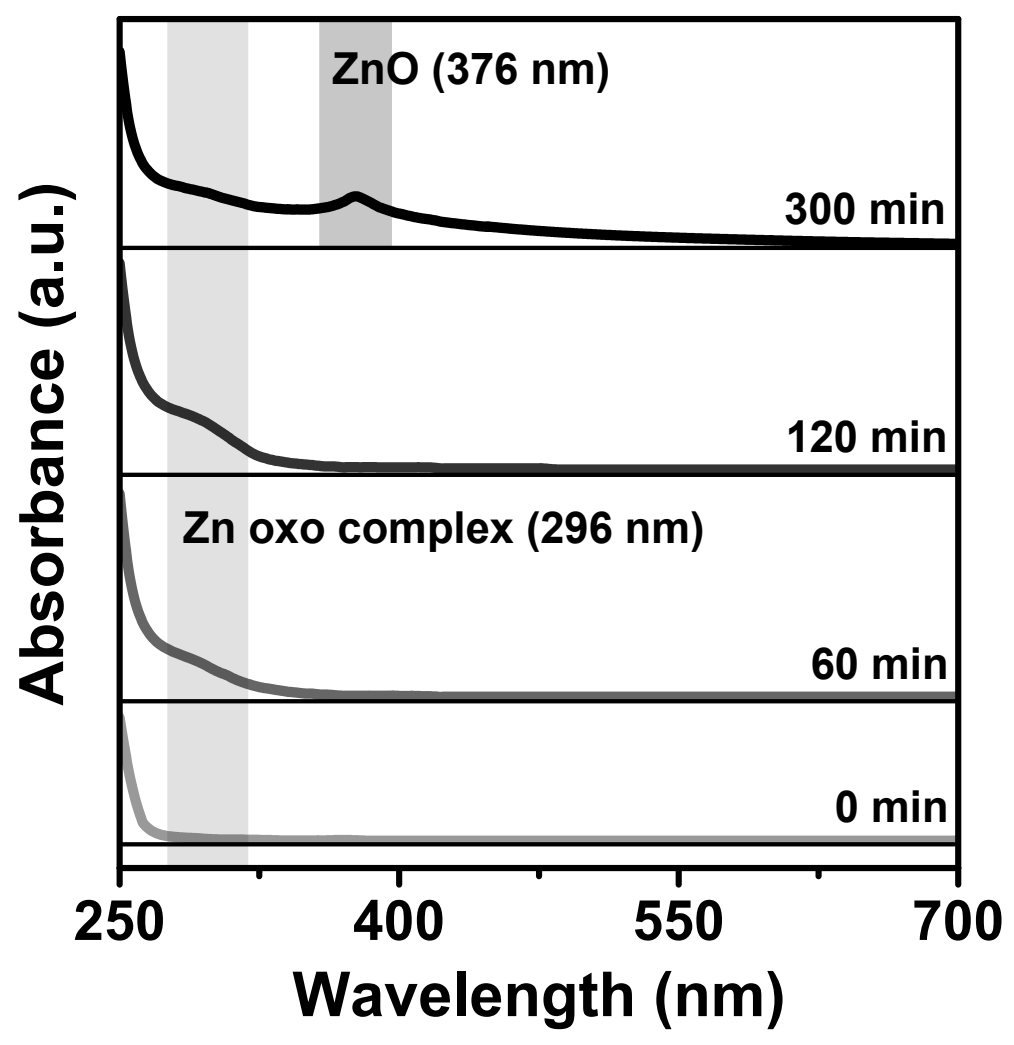

Figure S8. Observation of the changes of absorbance during thermolysis of zinc carboxylates

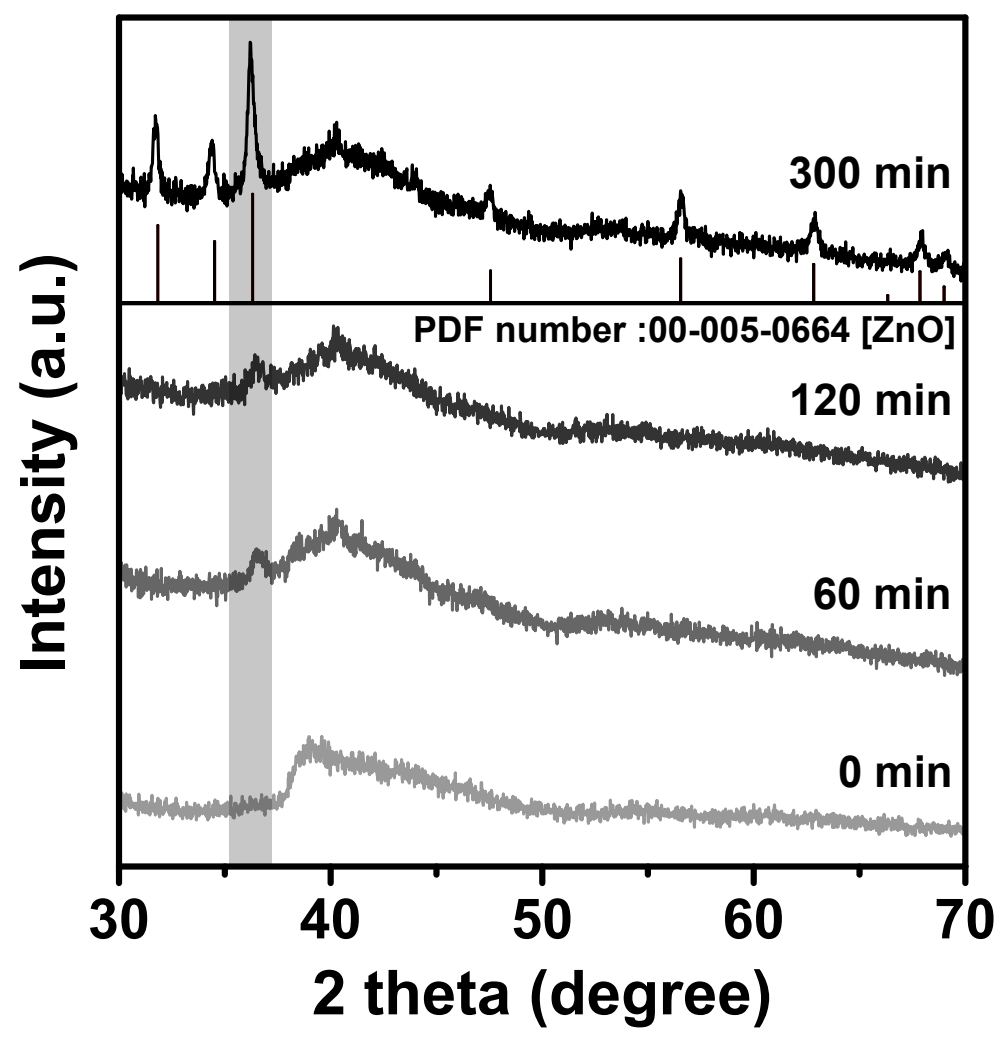

Figure S9. XRD results of zinc carboxylates' thermolyzed product with different decomposition time 


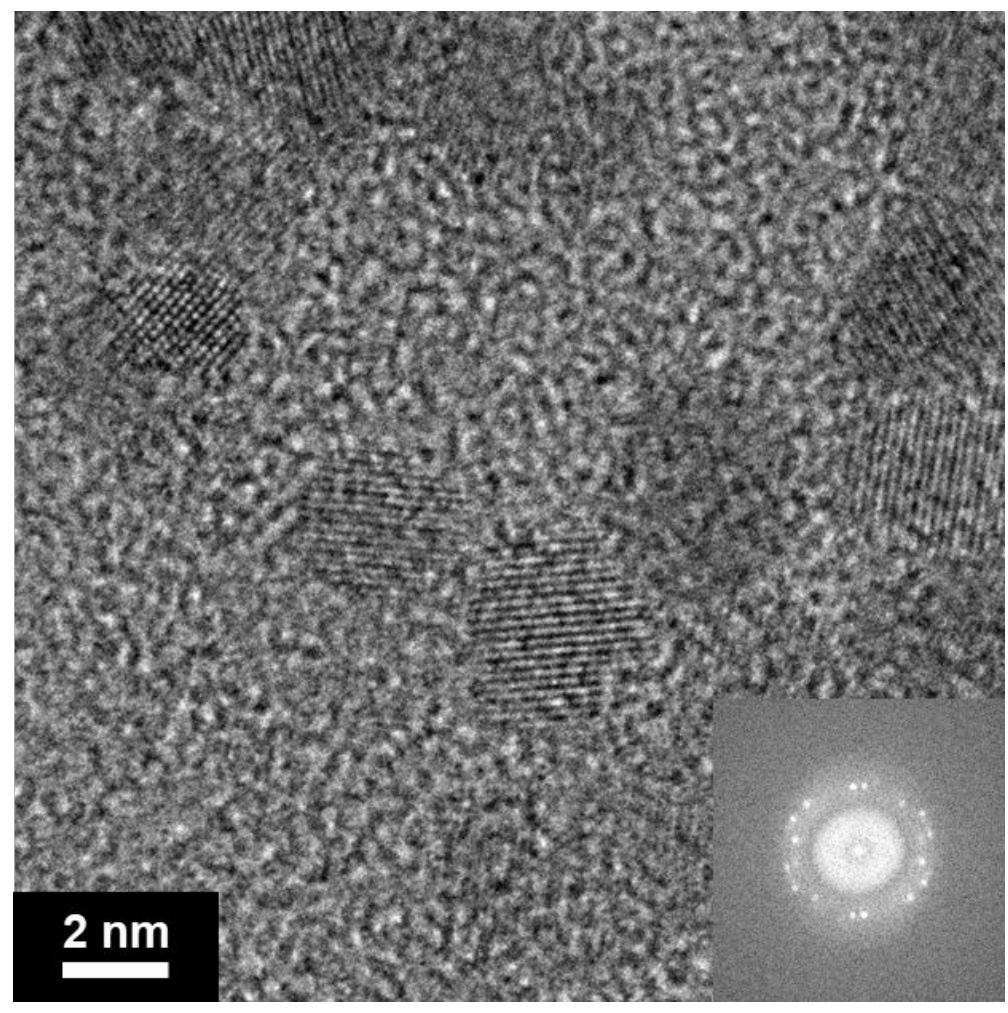

Figure S10. TEM images of ZnO NPs obtained by thermolysis
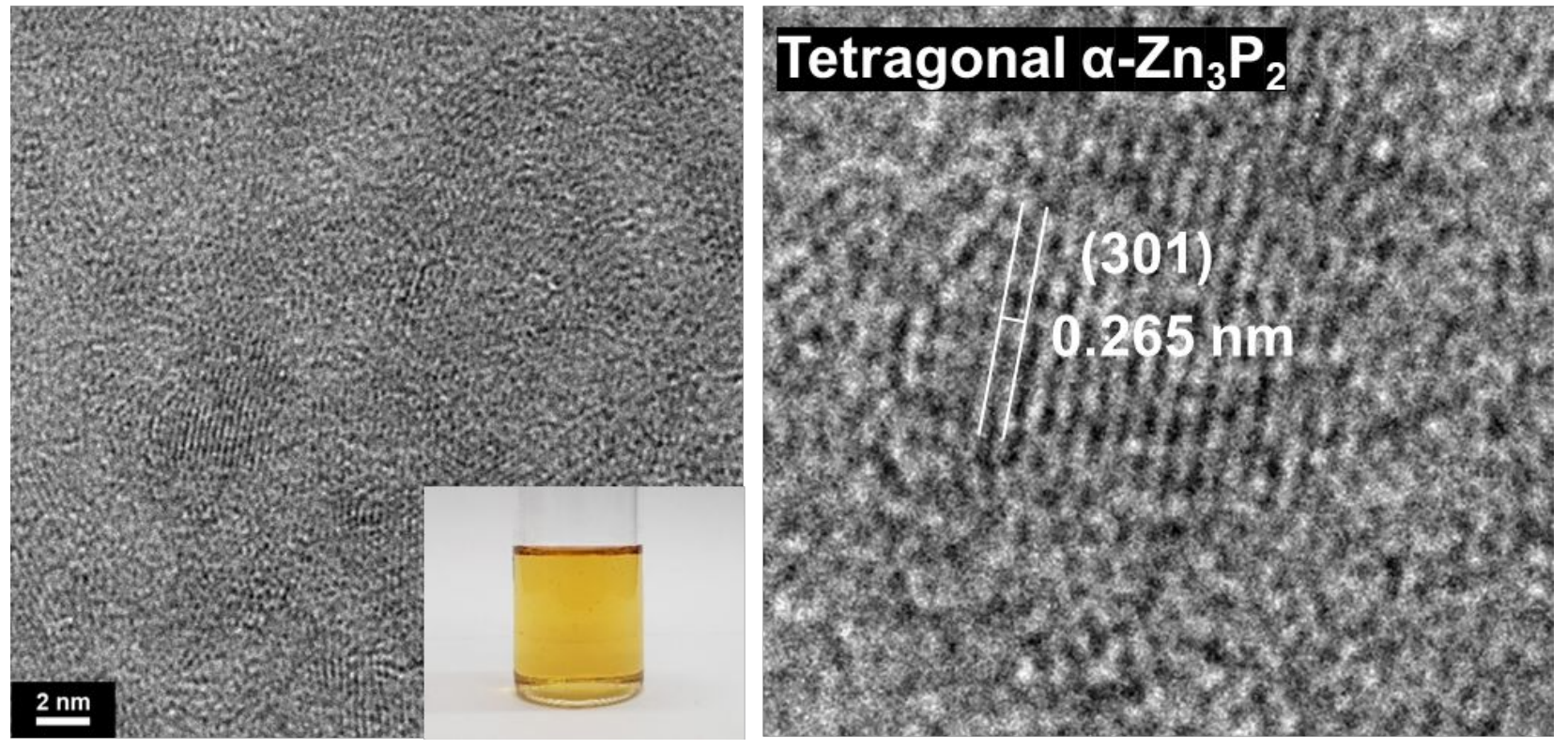

Figure S11. Photo images and TEM analysis of Zn-P complex 
(a)
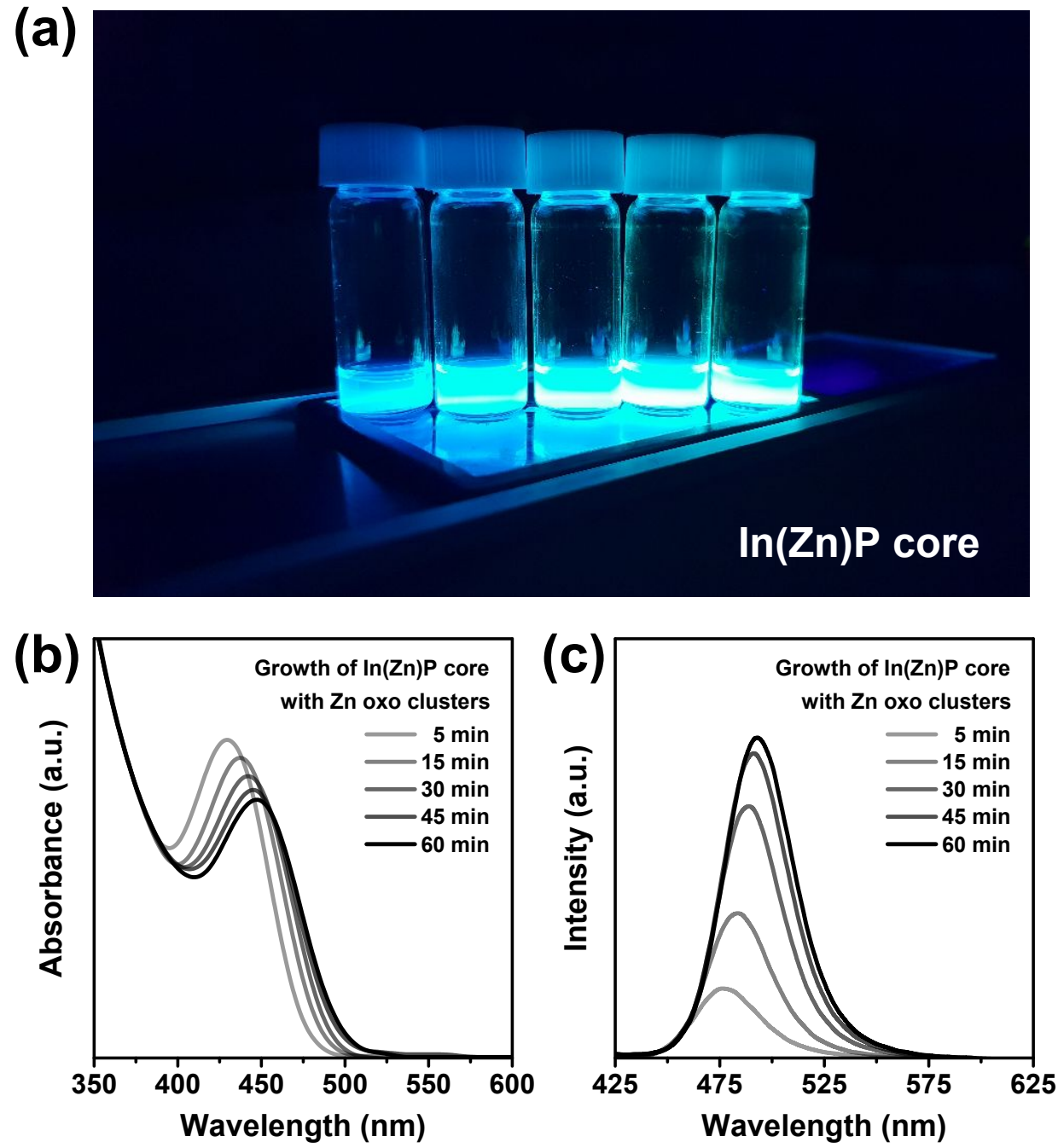

Figure S12. (a) Photoluminescence photographs under a UV lamp (365 nm), (from left) 5, 15, 30, 45, 60 min grown core respectively.

$(\mathrm{b}, \mathrm{c})$ Changes of UV-vis absorption and photoluminescence during an hour of $\operatorname{In}(\mathrm{Zn}) \mathrm{P}$ core growth.

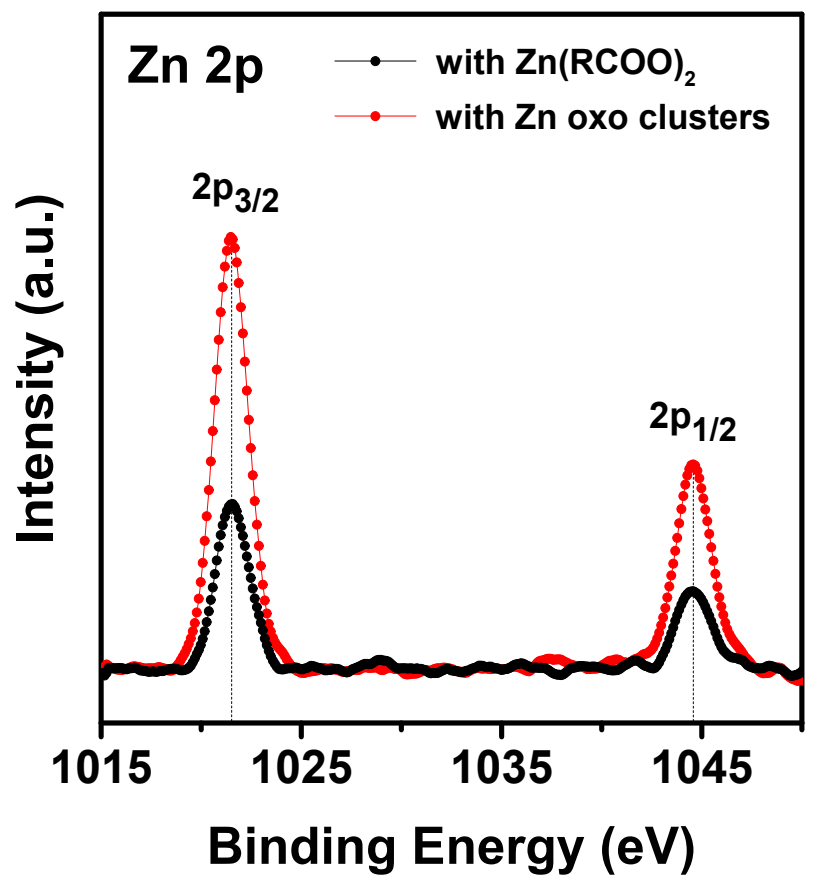

Figure S13. XPS characterization results of $\operatorname{In}(\mathrm{Zn}) \mathrm{P}$ cores' $\mathrm{Zn} 2 \mathrm{p}$ energy state 